\title{
Avanços e contradições da participação popular na definição de políticas públicas de lazer em Porto Alegre
}

\begin{abstract}
Resumo: O estudo situa o tema da participação cidadã nas reivindicacões por políticas públicas de lazer no município de Porto Alegre, tomando-se por base o ano de 2000. A pergunta central do estudo é: como se dá a participação da população na formulação das políticas públicas de lazer na cidade de Porto Alegre? Quais são as possibilidades e contradições dessa participação? Os dados analisados foram coletados através de questionários, documentos, entrevistas e observações. É possível dizer que em relação ao poder decisório da população na reivindicação e definição das políticas públicas de lazer, os avanços restringem-se às demandas surgidas nesta área. Houve um aumento de ações sistemáticas pela Secretaria Municipal de Esporte, Recreação e Lazer (SME) e avançou-se num processo de inversão de prioridades, criando espaços físicos em regiões da cidade que antes nada possuíam. No âmbito da política pública do município os avanços já são visíveis, contudo a política específica da SME apresenta contradições a serem resolvidas.
\end{abstract}

Palavras-chave: políticas públicas, lazer, participação cidadã.

\section{Introdução}

Este artigo enfoca as políticas públicas no campo do lazer em Porto Alegre, no ano de 2000. Tomamos a participação da população como principal categoria de análise, já que no modelo de gestão adotado por aquela administração esta foi central nos rumos da formulação e execução das políticas municipais.

No ano de 1988, com a vitória da Frente Popular em Porto Alegre, iniciava-se a "Administração Popular", nome pelo qual ficou conhecida. O discurso fundamental era o da ruptura com a ordem social vigente, pautando-se em três diretrizes principais: a inversão de prioridades, a democratização do acesso da população aos bens e serviços públicos e a descentralização do poder.

Movimento, Porto Alegre, v. 11, n. 3, p. 9-26, setembro/dezembro de 2005 
A participação foi entendida como a intervenção constante e homogênea da população que tem por objetivo atingir a efetividade das tomadas de decisão, tornando-as práticas sociais concretas, gerida desde o amadurecimento de posições políticas clarividentes.

Segundo Genro, esta participação será ampliada à medida que haja o fortalecimento de um "espaço público não-estatal" (1999b, p.41). A "Administração Popular" adotou o Orçamento Participativo (OP) como um canal diferenciado dos moldes de participação popular de décadas anteriores, que seguido por outros fóruns complementares, como o Congresso da Cidade, os Conselhos, as Conferências Setoriais, teceria uma intrincada teia de mecanismos que garantiriam a sustentação e ampliação deste espaço. Num primeiro momento, ainda na campanha eleitoral de 1988, a escolha recaía sobre a criação de Conselhos Populares. Esta idéia, segundo Augustin Filho, um dos autores que deu sustentação teórica a ações políticas da Frente Popular, resgatava uma "lucidez política com relação aos princípios que necessariamente deveriam ser considerados em um processo de democratização real do Estado. Embora a prática tenha se encarregado de fazer o Orçamento Participativo, e não os conselhos populares" (1994, p.50).

O discurso do setor responsável pelo campo do lazer estava em consonância com a política geral adotada. Ou seja, afirmava que iria superar políticas "clientelistas", privilegiando a participação direta mais efetiva e ativa da população na gestão local e na reconstrução de espaços autônomos, nos quais haveria alto grau de organização dos atores sociais, principalmente das camadas populares. Também apontava para uma mudança nas bases conceituais e ideológicas do lazer, que o coloca como uma prática voltada ao controle social, com estreito vínculo com as manifestações da cultura corporal, em especial aquelas ligadas ao esporte.

Até 1993 as políticas públicas de lazer em Porto Alegre estiveram vinculadas à Supervisão de Esportes e Recreação Pública (SERP), setor ligado à Secretaria Municipal de Educação (SMED). Após este ano, passaram a estar sob responsabilidade da Secretaria Municipal de Esportes, Recreação e Lazer (SME, que foi criada através da lei 7330).

Frente ao exposto, este estudo foi fundado num esforço de comprensão da participação da população na formulação de públicas de lazer na cidade de Porto Alegre. Procuramos, com esta discussão, trazer elementos para reflexão sobre a efetividade desta prática, seus

Movimento, Porto Alegre, v. 11, n. 3, p. 9-26, setembro/dezembro de 2005 
limites e avanços, alicerçando-nos nas próprias bases conceituais usadas por aquela administração.

Foram utilizados três instrumentos de coleta de dados: análise documental, observações e entrevista semi-estruturada.

A análise documental aconteceu em todos os documentos produzidos pelas reuniões do OP municipal durante o ano analisado, nos documentos resultantes do processo do OP do ano anterior, nos documentos produzidos pela SME e o plano geral de governo do município de Porto Alegre e numa pesquisa realizada pela Organização Não-Governamental Cidade sobre os participantes do OP.

As observações foram realizadas em todas as fases do OP municipal, nas plenárias temáticas (primeira e segunda rodadas), nas plenárias das regiões do extremo-sul e do centro, e nas rodadas intermediárias da plenária temática de "educação, esporte e lazer". A partir da primeira rodada do OP e da análise de documentos oficiais da administração municipal, elegemos duas comunidades para a análise de seu cotidiano. Os parâmetros desta escolha foram os equipamentos públicos de lazer existentes nas comunidades, as ações sistemáticas ou eventuais de lazer promovidas pelo poder público na região, as condições organizativas e participativas da população e o tempo de inserção que a mesma tinha nas discussões do OP. Optamos por escolher uma comunidade (do centro) que possui ações sistemáticas promovidas pela SME, um número grande de equipamentos de lazer, uma boa mobilização comunitária e uma inserção antiga nas discussões do OP e uma outra comunidade (da região extremo-sul) que, por ter sido considerada área rural até poucos anos atrás, não participava das discussões do OP. Passou a participar somente após ter sido transformada em zona urbana. Além disso, trata-se de comunidade que possui no seu entorno ótimos equipamentos ou espaços privados e públicos para o lazer, mas nos quais o poder público não possui ações sistemáticas e raramente promove eventos pontuais.

As entrevistas semi-estruturadas foram aplicadas a nove representantes ou ex-representantes da administração municipal e a seis líderes comunitários, três de cada comunidade observada.

Movimento, Porto Alegre, v. 11, n. 3, p. 9-26, setembro/dezembro de 2005 


\section{O orçamento participativo como fórum deflagrador da participação popular em Porto Alegre}

Na década de 1980, o cenário nacional concedeu espaço para duas conquistas em relação à participação: constituiu-se um campo democrático no interior da sociedade civil formado, sobretudo, pelos movimentos populares e pelos movimentos sociais pluriclassistas, que desenvolveu uma cultura política de mobilização e de pressão direta para encaminhar suas demandas e houve a abertura de canais de participação da população em assuntos que dizem respeito à administração pública.

Embora as conquistas tenham sido grandes, o eixo articulatório da participação continuou sendo o da ocupação de espaços físicos para que se fizessem ouvir outras vozes, além daquelas que estavam no poder.

por mais que se tenha pressionado as estruturas de poder então existentes, era uma pressão um tanto quanto passiva, pois se reivindicavam espaços sem qualificá-los bem, eram desejos, representações coletivas tidas como soluções para todos os males existentes. Por isto, o termo participação foi se generalizando de tal forma que se tornou vocábulo obrigatório no discurso de todos os políticos e nas diretrizes programáticas de todos os partidos e governos, independente da matriz e ou cor partidária (GOHN, 2000, p. 21 ).

No final da década de 1980 parcelas da oposição assumiram o poder estatal em várias cidades e estados, havendo uma requalificação gradual da temática participação. A lógica adotada se aproximava dos referenciais propostos por pensadores como Antonio Gramsci (1978,1980, 1981), Oskar Negt (1984), Carlos Nelson Coutinho (1981), que foram apropriados ao contexto do novo momento político brasileiro, em especial em Porto Alegre, por Tarso Genro (1999a, 1999b, 2001).

“A participação popular, no novo paradigma, passa a ser vista como uma intervenção social, periódica e planejada, ao longo de todo o circuito de formulação e implementação de uma política pública." (GOHN, 2000, p.24).

Para tanto, a sociedade civil precisará de independência para erigir um novo bloco histórico que definirá se a hegemonia ou o consenso irão se sobrepor à velha fórmula da coerção ou dominação. ${ }^{1}$

1 Coutinho trabalha os conceitos de dualidade de poderes e de Estado ampliado, advindos da Teoria de Gramsci, explicando que este autor não nega que entre as duas esferas (sociedade política e sociedade civil) há um momento unitário. Para

Movimento, Porto Alegre, v. 11, n. 3, p. 9-26, setembro/dezembro de 2005 
Organismos ou instituições na sociedade civil que possam dar conta de uma paulatina transformação do "Estado-coerção" em um "Estado-ampliado" deverão ser criados, tendo como mote a diluição deste último na sociedade civil. Para que isto ocorra Tarso Genro (2001) escreve que é preciso a participação de todos por meio do voto, no modelo da democracia representativa existente hoje, mas também que se criem instâncias garantindo aproximação e controle permanentes da população sobre seus representantes e sobre as instituições.

Haverá de existir, de acordo com Genro (1999a), a reconstrucão de uma "tensão democrática autêntica", que surgirá a partir de um novo espaço público. Este espaço público não está, nem na esfera do público e nem na esfera do privado, deverá ser um "espaço público não-estatal". "Um espaço que propicie a politização da cidadania, à medida que reduza sua fragmentação, integrando demandas setoriais na cena pública" (GENRO, 1999b, p. 41).

O conceito de "espaço público não-estatal" foi fundamentado nas discussões realizadas por Oskar Negt sobre esfera pública. Ele afirma que quando o conceito de esfera pública burguesa surgiu, sua finalidade era contrapor e romper com as práticas secretas e de encobrimento existentes no poder feudal. Contudo hoje, em países onde esta esfera pública burguesa parece ainda intocada, como é o caso do Brasil, ela tem sido minada por movimentos de greve, de massas empobrecidas que lutam pela sobrevivência e pela prevalência de alguns parcos direitos aos quais nunca tiveram acesso. Estes movimentos sociais, segundo o autor, não têm ainda força de sobrevivência para a formação sólida de uma esfera pública proletária. Vias de regra estes movimentos se desintegram e a força dos mesmos se exaure perante o forte aparato que possui a esfera pública burguesa. Oskar Negt (1984), quando fala da possibilidade da emergência de uma esfera pública proletária, que se

Gramsci o Estado, em sentido estrito, é um aparelho que tem legalmente o pode de coerção e o usa para manter o controle e a disciplina dos grupos que não consentem, nem ativa, nem passivamente ao direcionamento que é dado pelo bloco dominante. Contudo, o Estado moderno será menos coercitivo e mais consensual, ou vice-versa, dependendo do grau de autonomia relativa que consensual, ou vice-versa, dependendo do grau de autonomia relativa que as esferas assumirem. Segundo Coutinho "essa predominância, por sua vez, depende não apenas do grau de socialização da política alcançado pela sociedade em tela, mas também da correlação de forças entre as classes que disputam a supremacia" (1994 p. 57). Nesta mesma linha de reflexão, é possível observar que Gramsci, afirma a possibilidade de uma classe ainda não dominante no plano político ser dirigente no plano ideológico (COUTINHO, 1994) e, "torna-se não só possível, mas até necessário que a classe que se candidata ao domínio político já seja previamente hegemônica no plano ideológico, ou, na terminologia gramsciana, já detenha a direção intelectual e moral da sociedade" (COUTINHO, 1994, p.59).

Movimento, Porto Alegre, v. 11, n. 3, p. 9-26, setembro/dezembro de 2005 
organize em torno de interesses de emancipação dos homens, diz que o estabelecimento da mesma "choca-se frontalmente com os mecanismos de dominação da esfera pública burguesa" (1984, p. 36). Para ele a

esfera pública proletária é um processo de produção e não como a esfera pública burguesa, um procedimento de simples distribuição, de circulação de opiniões, de conhecimentos, de convicções. A esfera pública proletária sempre se forma historicamente ali onde os homens passaram, por necessidade material, espiritual ou intelectual, a discutir e a organizar na plena luz do dia os contextos importantes para sua vida [...] O que vem a se expressar na esfera pública proletária é a superação do medo do contato com as instituições e espaços definidos pelas classes dominantes. Se a esfera pública burguesa reside no fato de que nas universidades se ensine e aprenda, de que no tribunal se negocie, de que no parlamento se discuta, na esfera pública proletária que está surgindo perde-se esta fragmentação de espaço e tempo e surge um contexto no qual tudo que os homens necessitam para sua vida imediata é compreendido como interesse público (NEGT, 1984, p.37).

Negt ainda nos alerta para um ponto fundamental em relação à criação e sustentação de uma esfera pública proletária, que no caso deste estudo é de primordial interesse, pois podemos transportálo à manutenção e expansão do "espaço público não-estatal", quando escreve que

uma efetiva dialética entre esfera pública proletária e burguesa somente é possível num contexto político, se com cada passo em que se utiliza a esfera pública burguesa se articula a ampliação da autonomia e autodeterminação dos homens. Pois é justamente traço característico da esfera pública proletária que não pode mais ter nele lugar a política da representação (grifo nosso, 1984, p.40).

O OP foi adotado como fórum central, pela Frente Popular, para a solidificação do "espaço público não-estatal". Contudo, ainda paira uma grande dúvida sobre os limites desse tipo de prática, pois "até que ponto essa experiência não é percebida pelos indivíduos participantes como mais um episódio de cidadania concedida"? (FEDOZZI, 1999, p.201). A pergunta é complexa e certamente não será totalmente respondida por este estudo.

O processo de discussão do OP em Porto Alegre acontece praticamente o ano inteiro. É interrompido apenas nos meses de janeiro e fevereiro. A partir de março de cada ano, discutem-se as prioridades para o ano seguinte. Por exemplo, o processo ocorrido em 2000, no qual demandas foram priorizadas pela população, transformou-se em Plano de Investimento para o ano de 2001.

Existem plenárias regionais e temáticas. As regionais (em número de dezesseis hoje) promovem a discussão acerca dos proble-

Movimento, Porto Alegre, v. 11, n. 3, p. 9-26, setembro/dezembro de 2005 
mas das comunidades e bairros aglutinados, por critérios espaciais e populacionais, naquela região. Já as plenárias temáticas, criadas somente em 1994, são destinadas a pensar as prioridades para toda a cidade, pautadas em grandes temas emergentes. Em 2000 foram seis as temáticas abordadas: desenvolvimento econômico e tributação; saúde e assistência social; circulação e transporte; cultura; educação, esporte e lazer; e, organização da cidade, desenvolvimento urbano e ambiental.

O OP acontece em etapas distintas. Há uma primeira rodada de plenárias temáticas e regionais. Depois de alguns meses (em meados de junho) há uma segunda rodada, na qual serão definidas as prioridades e a aplicação dos investimentos públicos, que farão parte do texto do Plano de Investimentos da Administração Municipal. Entre a primeira e a segunda rodada, há uma rodada intermediária, para que as comunidades se organizem como acharem melhor (por bairros, associações ou sociedades profissionais, somente para citar algumas) a fim de discutir e definir suas reivindicações regionais e temáticas, que posteriormente serão levadas à segunda rodada do OP.

Após este período acontecem as reuniões do Conselho do OP $(\mathrm{COP})^{2}$ em conjunto com o Gabinete e Planejamento da Prefeitura (GAPLAN) e Centro de Relações Comunitárias (CRC) para a definição da proposta orçamentária a ser encaminhada à Câmara de Vereadores. Enquanto a Câmara discute a proposta, o COP se reúne com as secretarias para definir o Plano de Investimentos e, por fim, mesmo depois de definido aonde serão investidas as verbas disponíveis, o COP continua trabalhando questões organizativas ou seu próprio regimento interno, reavaliando critérios técnicos e gerais e fiscalizando as obras que estão em andamento e as que deverão ser iniciadas.

Além do OP, existem outros fóruns, de caráter mais pontual, nos quais a população pode exercer sua participação, como o Congresso da Cidade e as Conferências Setoriais. A população também pode se dirigir às secretarias de governo ou aos Centros Administrativos Regionais, levando demandas específicas.

2 Segundo a Prefeitura Municipal de Porto Alegre o COP é composto de: dois conselheiros titulares e igual número de suplentes eleitos em cada uma das dezesseis regiões da cidade, dois conselheiros titulares e igual número de suplentesesseis egioes da cidade, dois conselheiros titulares e igual número de suplentes eleito em cada uma das cinco estruturas temáticas, por um representante titular e um suplente do Sindicato dos Municipários de Porto Alegre e por um representante titular e um suplente da União das Associações de Moradores de Porto Alegre. Os representantes do governo são em número de dois, os quais não possuem direitos a voto $(1999$, p. 2).

Movimento, Porto Alegre, v. 11, n. 3, p. 9-26, setembro/dezembro de 2005 
É fundamental salientar que as comunidades e as associações de bairro, num modelo de expansão da participação, visando emancipação da sociedade civil e diluição do Estado, deveriam manter sua autonomia e seus movimentos organizados. Porém, na prática do OP reside uma contradição pois, se como afirmam pesquisadores como Fedozzi (1999) e Abers (1997), este fórum promove condições institucionais favoráveis à emergência da forma-cidadania (FEDOZZI, 1999) e tem transformado o "clientelismo local, indo além das mudanças nas regras fazendo mais do que mudar regras sociais"(ABERS, 1997, p. 310) também tem desmobilizado organizações centrais da cidade que poderiam fazer o contraponto ao processo do OP, como podemos constatar no depoimento de B.

[...] pela característica que tinha a experiência (do OP - grifo nosso), ela esvaziou, de certa forma, as entidades mais centrais da cidade. Então, por exemplo, a UAMPA (União e Associação dos Moradores de Porto Alegre), que foi fundamental na disputa pela criação dum instrumento (o entrevistado refere-se ao OP) como esse, de certa forma hoje perdeu a sua capacidade de representar. Eu diria que isso não é só um problema político, isso tem a ver também com um problema estrutural, porque as associações, as organizações, comunitárias, vem à arena pra resolver suas questões, [e este processo] não é mais dentro da UAMPA, mas dentro do conselho participativo. Eu acho que isso é um limite, porque é importante você ter entidades representativas com capacidade de mobilização e que façam um contraponto por fora, que não seja só o conselho do orçamento [...] um movimento comunitário, deve ter capacidade crítica, ser autônomo, independente, vamos dizer assim, de certa forma, sirva como local aonde os movimentos sociais vão dialogar e fazer seus consensos, seus pactos para disputarem dentro do orçamento também. (Depoimento oral, 2000).

Com base neste depoimento, podemos inferir que no modelo de participação adotado em Porto Alegre, as comunidades podem se organizar mas só terão força caso disputem suas necessidades dentro do OP.

Pensando mais sobre participação no OP e em outros fóruns é preciso refletir sobre a maior ou menor capacidade que a população tem de exercer seu poder de decisão. Então, além de analisarmos as contradições presentes no processo do OP, temos que entender qual a capacidade, o espaço e a disposição da população para assumir o poder de decisão e como ele é exercido na realidade observada.

As observações nos permitiram identificar diferentes tipos de lideranças comunitárias presentes nestes fóruns. Um primeiro grupo de lideranças efetivamente esgota a sua participação comunitária neste processo, ou seja, vem à arena exclusivamente para reivindicar melhorias específicas para sua comunidade. Muitas destas lideranças chegam a ponto de convidar qualquer pessoa presente às reuniões para compor um grupo, atingindo o número

Movimento, Porto Alegre, v. 11, n. 3, p. 9-26, setembro/dezembro de 2005 
necessário (no caso do OP são dez pessoas para indicar um representante) para lutar por sua demanda. Um segundo grupo efetivamente transforma-se durante o processo. Chega ao OP ou a outro fórum semelhante, buscando a solução de uma demanda imediata de sua comunidade, mas envolve-se com o processo, aprende, cresce e estabelece uma dinâmica de retorno deste aprendizado junto aos seus pares. Por fim, há um terceiro grupo de lideranças que poderia ser classificado como de lideranças emergentes, ou seja, aqueles líderes comunitários que surgiram com o próprio OP. Geralmente estas lideranças têm dois destinos, ou usam este fórum como "trampolim" para uma vida de político profissional, ou procuram através deste aprendizado ajudar sua comunidade e a cidade.

Em questionário, aplicado pela ONG Cidade (2002) aos participantes do OP, durante o ano de realização deste estudo, quando os entrevistados foram perguntados se participavam do OP $81,8 \%$ dos respondentes disseram não participar. Quando questionados sobre sua disponibilidade em participar, $60,3 \%$ responderam que não gostariam de participar, apontando como motivos: não terem idade, não gostarem, não acharem necessário para as suas vidas, acharem que tudo é "politicagem", não gostarem do PT, terem divergências de idéias com o processo, acharem uma bobagem, não gostarem de política, acharem que tudo já está arrumado ou já tiveram decepções com o processo.

Contudo não há só descrédito da população em relação a estes fóruns; nas observações e nos depoimentos foi possível perceber otimismo e mudança de atitudes.

Tomando trechos de entrevistas, é possível perceber que o OP é visto como um processo importante para o exercício da participação, apesar de existirem muitas dificuldades a serem superadas. Exemplo disto pode ser percebido nestas passagens dos depoimentos orais, quando o entrevistado fala dos avanços proporcionados pelo processo do OP " houve a abertura de portas da prefeitura para a população porto-alegrense. Eles transformaram a cidade numa imensa escola de cidadania". E continua afirmando que a população não fica mais à espera dos governantes; ela passou a agir. "Além de ir lá e decidir sobre a receita e a aplicação do dinheiro, nós estamos também fiscalizando todos os trabalhos que são decididos pelo OP".“O OP, na verdade, conseguiu conquistar esse processo de participação, de ampla participação popular. É bem verdade que alguns desafios ainda se colocam; algumas questões ainda precisam ser aprofundadas nesta relação do poder público com a comunidade".

Movimento, Porto Alegre, v. 11, n. 3, p. 9-26, setembro/dezembro de 2005 
Uma estratégia que tem sido adotada por todas as secretarias, favorecendo as comunidades e cumprindo-se o papel fundamental de qualificação da demanda, é o contato que o responsável pela Assessoria Comunitária (ASSCOM) tem desempenhado junto delas.

Quando observamos as comunidades procuramos enfatizar em nosso olhar a presença e atuação da Secretaria responsável pelo lazer em Porto Alegre. Desta forma, verificamos como acontecia a atuação da ASSCOM da SME e qual era o real potencial e disponibilidade que a população tinha para exercer seu poder de decisão. Surgiram então alguns limites claros tanto da atuação, quanto do exercício do poder de decisão em relação ao campo deste estudo.

\section{Qual é o espaço do lazer?}

Para refletirmos sobre o lazer tomamos por base as reflexões de Mascarenhas quando este diz que

É preciso ressaltar, no entanto, que a relação dialética entre estrutura e superestrutura - ou seja, a própria idéia de bloco histórico - pressupõe que a função hegemônica ultrapasse os limites de uma ação restrita ao plano cultural, devendo se articular, para ser autêntica, ao nível da realidade socioeconômica [...] Ao se pensar nas relações de hegemonia implícitas ao lazer-educação, qualquer intervenção em grupos sociais, para a melhoria do seu nível cultural e social, a partir da idéia de coesão e esforço conjunto, não deve ignorar o antagonismo de interesses originários das contradições do modo de produção capitalista (2003, p.20-21).

A partir desta reflexão nos aproximamos das bases que Mascarenhas (2003) propõe para o lazer-educação. Pensamos que estas devam também dar sustentação a um projeto de sociedade que busca autonomia e superação da ordem vigente. O autor propõe que o lazer deva ter uma "intencionalidade, uma temporalidade e uma organização" (MASCARENHAS, 2003, p.22) e, a perspectiva da educação popular, ou seja, deve ser uma "prática para a liberdade" (MASCARENHAS, 2003).

Outra observação importante a respeito do lazer é pensá-lo como uma ação política que abrange mais do que o vínculo com uma secretaria de governo. Quanto à alocação do lazer, a "Administração Popular" em Porto Alegre não fez inovações. A responsabilidade por este campo continua sendo de uma secretaria ligada ao esporte.

Assim como na Constituição de 1988, a lei Orgânica do $\mathrm{Mu}$ nicípio de Porto Alegre, promulgada em 03 de abril de 1990, também dispõe sobre o lazer.

Movimento, Porto Alegre, v. 11, n. 3, p. 9-26, setembro/dezembro de 2005 
No caso específico do lazer no OP, há uma temática de educação, esporte e lazer específica e um coordenador. É este que chama, em consonância com as necessidades da população participante, as reuniões da rodada intermediária para qualificar a discussão da temática. O coordenador temático da educação, esporte e lazer mantém contato direto com a assessoria comunitária das Secretarias de Educação e da SME para que as mesmas intercedam nas comunidades e tragam subsídios teóricos e técnicos que qualifiquem a discussão específica.

Em 2000, no final da priorização por demandas temáticas, nenhuma das reivindicações do lazer foi eleita como uma das principais prioridades. Em primeiro lugar foi apontada a pavimentação, em segundo, a habitação e em terceiro, o saneamento básico.

Também constatei, em documentos da SME analisados, uma dotação orçamentária baixa para o setor, um quadro de recursos humanos precário, políticas públicas de lazer que muitas vezes não são devidamente valorizadas em todos os setores da administração municipal e as reduzidas demandas advindas da população.

A constatação dos limites conceituais sobre lazer na população porto-alegrense permite-nos afirmar que esta também é uma situação contraditória para a reivindicação destas políticas públicas. Constatamos que o lazer é entendido como supérfluo pela população ou deve ficar restrito ao campo da opção pessoal e de iniciativa individual. Bem, se os cidadãos o entendem como uma opção individual e subjetiva, não o colocam entre as prioridades demandadas, haverá poucas reivindicações de lazer nos fóruns de participação da cidade. A SME - que tem a responsabilidade direta por estas ações - e outros setores da administração municipal, devem disporse a trabalhar as comunidades para mudar este quadro. Contudo, será necessário primeiro mudar as bases conceituais que sustentam as argumentações dos quadros internos da PMPA.

Limites como o número de funcionários da SME, a forma como a co-gestão é conduzida e assumida pelas comunidades, a base conceitual do lazer que dá sustentação às ações e os significados que o lazer tem para a população foram algumas contradições encontradas nesta área.

O número de funcionários da SME é pequeno para atender o número crescente de demandas. As comunidades, após um processo de co-gestão, ${ }^{3}$ deveriam assumir os projetos ou programas

3 Nas sociedades democráticas e industriais a co-gestão foi estabelecida como uma possibilidade da participação do cidadão numa sociedade política, mas também do trabalhador numa comunidade econômica. É possível afirmar que, entre a

Movimento, Porto Alegre, v. 11, n. 3, p. 9-26, setembro/dezembro de 2005 
com autonomia, rumo à auto-gestão, porém o que tem acontecido é o esmorecer das ações propostas. Há ainda nas comunidades a necessidade de que a administração perpetue-se como concedente do espaço, dos materiais e seja incentivadora das ações. Além disso, em muitas regiões, dada a precariedade de outras políticas e uma visão alicerçada na idéia de que o lazer deve ser uma atitude espontânea e responsabilidade individual, as comunidades não reivindicam políticas para esta área.

Outro problema constatado em relação à co-gestão pode ser observado em documento oficial da SME. Ao falar de co-gestão o documento diz que o principal objetivo é "conscientizar e estimular as pessoas para assumirem a responsabilidade de construção, manutenção e qualificação dos espaços públicos e das atividades ali desenvolvidas, democratizando-os pela participação" (SME, 2001, p.6). Porém, em outra passagem deste mesmo documento, quando se remete à responsabilidade das comunidades, o entendimento do conceito de co-gestão dá espaço à cobrança de taxas, já que esta prática é encarada de forma natural pela secretaria.

Além disso, em depoimentos tomados de líderes do governo nos foi possível perceber que entre o discurso geral de co-gestão da administração municipal e da SME há uma distância conceitual, o mesmo acontece entre a teoria e a prática da SME sobre o mesmo assunto.

O que a SME tem exercido pode ser caracterizado mais como uma prática de parceria, na qual cada parceiro se responsabiliza pela execução de sua parte, com contribuição financeira e com independência de suas ações. Como no estabelecimento de parcerias, o parceiro mais forte é quem determina as "regras do jogo"

heterogestão que representa a total exclusão do cidadão das decisões políticas e econômicas, pois a decisão fica nas mãos de quem detém o capital e a autogestão, "que esparge o processo decisório no seio e, em princípio, entre todos os participantes da organização, pela atuação direta nos conselhos e nas assembléias onde se formulam as decisões" (MARTINS, 1987, p.178) está a co-gestão, entendida como forma híbrida. Os graus de participação podem variar quando se fala de co-gestão, porém não é possível afirmar que estes graus levem à autogestão, senão, a possibilitar bases para que uma ruptura aconteça, pois "autogerir não é democratizar a economia capitalista, mas mudar seus fundamentos, ou neja, autogerir a economia é determinar quais são os produtos úteis aos, ou seja, autogerir a economia é determinar quais são os produtos úteis aos homens e não os que permitirão aumentar ao máximo o lucro da classe proprietária ou o poder do Estado centralizado" (MARTINS, 1987, p.179). Pois bem, a opção que a Frente Popular fez em relação a assumir parte do poder do Estado, sem a devida mudança do sistema social, determinou que a forma mais adequada de entender as ações que acontecem conjuntamente entre comunidades organizadas e espaços institucionalizados pelo poder público é estabelecer a gestão partilhada (co-gestão).

Movimento, Porto Alegre, v. 11, n. 3, p. 9-26, setembro/dezembro de 2005 
e, neste caso, o parceiro mais forte ainda é a administração municipal, a SME, então é ela quem "dita" tais regras, ficando as comunidades, na maioria das vezes, à mercê e à espera dessas iniciativas. Seria injusto de nossa parte não dizer que há sim movimentos sociais que têm mantido sua independência, contraposto e questionado as ações da administração municipal, mas na área do lazer, tais movimentos não adquiriram força suficiente para exercer esta função.

Avanços em relação aos espaços de lazer, ligados à gestão da SME, podem ser notados na descentralização das atividades, na revitalização dos espaços já existentes, que se encontravam em condições de precarização e desviados de sua vocação, como é o caso da recente incorporação dos Centros de Comunidade à administração direta da secretaria.

\section{Palavras finais}

O que nos levou a realizar este estudo e o orientou durante o período de observações e entrevistas, foi contribuir para uma reflexão que pudesse tecer subsídios ao avanço conceitual e na intervenção no campo do lazer, especialmente ligado às políticas públicas. Optamos por analisar uma realidade que tem sido anunciada como das que mais avançou em relação às práticas anteriores e que proporciona a participação da população na formulação e acompanhamento das políticas.

Quanto à primeira premissa, podemos afirmar que há avanços claros e, hoje, muitos bairros possuem atividades de lazer promovidas pela SME. Outros, possuem predisposição para o lazer ( seja pelo espaço físico que possuem, seja pelo entorno natural seja pela vontade da população) que é aproveitado no trabalho de ação comunitária dos técnicos responsáveis pela área.

Entretanto, em relação à participação podemos afirmar que apesar da forma usada pela Frente Popular ser bem mais abrangente do que décadas anteriores, ainda esbarra em contradições e limites, colocados na própria prática e erigidos pela maneira como a cidadania brasileira vem sendo exercida durante o decorrer de todo o século passado. Precisamos retomar a premissa de Negt em relação à sustentação do espaço público não-estatal, ou seja, em “cada passo em que se utiliza a esfera pública burguesa se articula a ampliação da autonomia e autodeterminação dos homens. Pois é justamente traço característico da esfera pública proletária que não pode mais ter nele lugar a política da representação" (NEGT,

Movimento, Porto Alegre, v. 11, n. 3, p. 9-26, setembro/dezembro de 2005 
1984, p.40). É fundamental garantir que estes fóruns de participação não desmobilizem, nem cooptem, os movimentos sociais que poderiam fazer o contraponto por fora das instâncias oficiais.

Em relação ao campo específico do lazer, como a população ainda o entende como uma prática supérflua às ações da iniciativa pública, será preciso um extenso trabalho de aproximação e ressignificação daquelas práticas culturais e populares já em esquecimento. É fundamental que as comunidades incorporem o lazer como um aspecto fundamental de suas vidas, cultivado como "uma prática de liberdade coletiva" que pode e deve ser proporcionada pelo poder público.

As ações levadas à sociedade pelo setor responsável, por vezes, estão permeadas ainda de uma lógica instrumental, estando assim a serviço da manutenção do status quo. O conceito de lazer, como prática educativa, ainda se coloca no campo exclusivo da mudança de um ethos cultural. Desta forma, per si esta prática não permitirá que a população tome consciência da luta de classes e organize-se autonomamente rumo a uma sociedade civil gerida pelos indivíduos em seu coletivo.

Embora a co-gestão da SME seja anunciada como uma ação importante para autonomia, da forma como ela está sendo conduzida no campo do lazer, pode aprofundar ainda mais as disparidades sociais. Para superar esta contradição será necessário retomar alguns princípios da co-gestão, ou seja, voltar a entender que co-gerir "não é democratizar a economia capitalista, mas mudar seus fundamentos, ou seja, autogerir a economia é determinar quais são os produtos úteis aos homens e não os que permitirão aumentar ao máximo o lucro da classe proprietária ou o poder do Estado centralizado" (MARTINS, 1987, p.179).

Por fim, sugerimos que as políticas de lazer sejam pensadas como uma política de governo ou com ações para ensejar uma transversalidade ou inter-setorialidade com outros órgãos da administração pública, além daquele nominalmente responsável pelo lazer.

Movimento, Porto Alegre, v. 11, n. 3, p. 9-26, setembro/dezembro de 2005 
Improvement and contradiction of citizenship participation on the public policies definition in Porto Alegre city

Abstract: The study situates the theme of citizenship participation on the claiming for leisure public policies in Porto Alegre city, taking as base the year of 2000. The study central question is: How does the popular participation on the leisure public policies formulation in Porto Alegre city is done? Which are the possibilities and limits of this participation? Data analyzed were collected throughout questionnaires, documents, interviews, and observations. It is possible to say that in relation to the population decision power on the claiming and definition of leisure public policies, advances are restricted to the demands arouse within this area. There were a raise of systematic actions by the Secretaria Municipal de Esporte, Recreação e Lazer -SME (General Municipal Office of Sports, Leisure and Recreation) and advanced into a priorities inversion, creating physical spaces in city regions that did not have anything before.

Keywords: public policies, leisure, and citizenship participation.

\section{Posibilidades y contradicciones de la participación de la población en la formulación de políticas publi- cas de ocio en la ciudad de Porto Alegre \\ Resumen: El estudio situó el tema de la participación de la ciudadanía en las reivindicaciones para políticas publicas de ocio en el municipio de Porto Alegre, siendo basado el análisis en el año de 2000. La pregunta prin- cipal del estudio es: ¿Cómo se dará la participación de la población en la formulación de políticas publicas de ocio en la ciudad de Porto Alegre? ¿Cuáles son las posibilidades y contradicciones de esa participación? Los datos analizados fueran recolectados a través de cuestionarios, documentación, entrevistas y observa- ciones. Opté por utilizar la técnica de triangulación en el análisis de los datos, por lo cual en todo el texto hay un constante diálogo entre la teoría y la realidad, y entre las diferentes fuentes de pesquisa. Es posible decir que en relación con el poder de decisión de la población en la reivindicación y definición de las políticas públicas de ocio, los avances están restringidos debido a las deman- das que surgirán en esta área.}

Palabras-clave: políticas publicas, ocio, participación de la población. 


\section{Referências}

ABERS, Rebbeca, (1997). Inventing local democracy: neighborhood organizing and participatory policy-making in Porto Alegre - Brazil. Thesis (Doctorade of Philosophy in Urban Planning) - University of California, Los Angeles.

AUGUSTIN FILHO, Arno. (1994), "A experiência do OP na Administração Popular da Prefeitura Municipal de Porto Alegre", in: C. Horn, Porto Alegre: o desafio da mudança. Porto Alegre, Ortiz.

COUTINHO, Nelson, (2000), Contra a corrente: ensaios sobre democracia e socialismo. São Paulo, Cortez.

(1994) Marxismo e Política: a dualidade de poderes e outros ensaios. São Paulo, Cortez.

. (1981) Gramsci. Porto Alegre, LP \& M.

FEDOZZI, Luciano (1999) Orçamento Participativo: Reflexões sobre a experiência de Porto Alegre. Porto Alegre, Tomo Editorial; Rio de Janeiro, Observatório de Políticas Urbanas e Gestão Municipal.

GENRO, Tarso (2001), "Instituições políticas no socialismo" In: Luiz Inácio Lula da Silva, Debates sobre o socialismo. São Paulo, Fundação Perseu Abramo.

(1999 a) O futuro das cidades na nova ordem global. Seminário de Democracia Participativa. Porto Alegre, PMPA.

. (1999 b) O futuro por armar: democracia e socialismo na era globalitária. Petrópolis, RJ, Vozes.

GOHN, Maria da Glória, (2000), "O cenário da participação em práticas de gestão da coisa pública no Brasil", in: UFSC, Motrivivência, Florianópolis, ano XI $-\mathrm{n}^{\circ} 14$.

GRAMSCI, Antonio. (1981), Concepção dialética da história. Rio de Janeiro, Civilização Brasileira.

. (1980). Maquiavel, a Política e o Estado Moderno. Rio de Janeiro, Civilização Brasileira.

_. (1978). Cartas do Cárcere. Rio de Janeiro, Civilização Brasileira.

MARCELLINO, Nelson Carvalho (1987) Lazer e educação. Campinas, SP, Papirus.

MASCARENHAS, Fernando, (2003). Lazer como prática de liberdade. Goiânia, UFG.

MARTINS, Paulo Matos, (1987). Participação na gestão: o discurso oficial brasileiro Dissertação de mestrado, RJ Escola Brasileira de Administração.

NEGT, Oskar, (1984) Dialética e história: crise e renovação do marxismo. Porto Alegre, Instituto Goethe.

Movimento, Porto Alegre, v. 11, n. 3, p. 9-26, setembro/dezembro de 2005 
ONG CIDADE. Quem é o público do OP 2000. Porto Alegre: ONG Cidade, 2002. TRIVIÑOS, Augusto N. da S (1987) Introdução à pesquisa em Ciências Sociais. A pesquisa qualitativa em educação. São Paulo, Atlas.

Recebido em: 31.08 .05 Aprovado em: 07.11.05

* Departamento de Educação Motora, Faculdade de Educação Física da Universidade Estadual de Campinas. E-mail: scfa@fef.unicamp.br

Movimento, Porto Alegre, v. 11, n. 3, p. 9-26, setembro/dezembro de 2005 